\title{
ESTUDO DA UTILIZAÇÃO DA PALHA DE CAFÉ COMO ADSORVENTE DE RESÍDUOS OLEOSOS
}

\author{
R. F. NASCIMENTO, L. F. CREMASCO, J. X. LACERDA, S. M. S. ROCHA e P. S. S. \\ PORTO
}

Universidade Federal do Espírito Santo, Departamento de Engenharias e Tecnologia

E-mail para contato: pssporto@gmail.com

RESUMO - A operação de adsorção vem ganhando destaque no tratamento de efluentes orgânicos e metais pesados, devido à sua eficácia. No tratamento de efluentes por adsorção os materiais indesejados, quer na forma líquida ou sólida presentes no efluente, são transferidas para a superfície de uma substância sólida. Porém esta técnica ainda é inviável economicamente em larga escala devido ao custo dos adsorventes, desta forma métodos alternativos, como utilização de resíduos agroindustriais vêm sendo estudados como material bioadsorvente. Como a região Norte do Espírito Santo é uma das principais produtoras de café, este trabalho tem como objetivo estudar o uso da palha de café como bioadsorvente na remoção de óleos e graxas de efluentes oleosos. Inicialmente se investigou qual o melhor $\mathrm{pH}$ para a adsorção do óleo. Nna etapa seguinte, o pH ótimo foi fixado para que então se avaliasse os efeitos da concentração de bioadsorvente e do tempo de contato. Verificou-se que a concentração de bioadsorvente e tempo de contato são fatores que influenciam de forma dependente, independentemente no processo adsortivo de óleos e graxas em casca de café. Também foi possível observar um percentual de remoção mínimo de $50 \%$ em todos os testes. Isto comprova que a casca de café é um potencial material adsortivo para óleos e graxas.

\section{INTRODUÇÃO}

Mesmo em pequenas quantidades, os contaminantes orgânicos são difíceis de serem removidos, pois são estáveis à luz, ao calor e biologicamente não degradáveis; diminuem a área de contato entre a superfície da água e o ar atmosférico impedindo a transferência de oxigênio da atmosfera para a água, bem como a incidência de luz solar, impedindo a fotossíntese, bem como apresentarem problemas estéticos. Desta forma os efluentes oleosos passaram a ganhar destaque na busca por tratamentos eficazes na remoção principalmente de óleos emulsionados. Neste contexto inúmeros tratamentos já são empregados pelas indústrias a fim de remover tais contaminantes de seus efluentes. Dentre os utilizados, a adsorção tem despertado bastante o interesse de pesquisadores e técnicos, por ser um processo eficaz para tratamento de efluentes orgânicos e metais pesados (Santos et al., 2007), porém inviável economicamente para ser aplicado em grande escala. 


\section{9 a 22 de outubro de 2014 \\ Florianópolis/SC}

Adsorção é um processo físico/químico no qual as partículas de substâncias líquidas ou sólidas são transferidas para a superfície de uma substância sólida. Esta transferência ocorre devido ao gradiente de concentração entre o adsorvato e o adsorvente. O processo é mais eficiente quanto maiores forem a superfície do adsorvente e a concentração do adsorvato e menor a temperatura (Fagundes et al., 2010). Existem dois processos de adsorção que podem ser distinguidos de acordo com as forças envolvidas: a adsorção física e adsorção química. $\mathrm{Na}$ primeira, as moléculas adsorvidas são retidas na superfície do adsorvente por forças fracas de Van der Waals e há a formação de multicamada. Na segunda, uma única camada de moléculas, átomos ou íons é unida, na superfície do adsorvente, por ligações químicas (Peruzzo, 2003).

Vários materiais adsorventes têm sido utilizados para a adsorção de contaminantes orgânicos e metais pesados. O carvão ativo é um dos mais empregados, principalmente por apresentar grande capacidade de adsorção. Possui, contudo, um elevado custo industrial, abrindo espaço para novos materias. A fim de reduzir o alto custo dos processos adsortivo, métodos alternativos têm sido estudados, entre estes, a biossorção, definida como adsorção utilizando resíduos naturais (Santos et al., 2007).

A utilização desses resíduos mostra-se interessante uma vez que se observa um distanciamento da proporção de crescimento das atividades agrícolas e desenvolvimento de tecnologias para a utilização econômica dos resíduos gerados e de cuidados com os impactos ambientais causados pelo seu acúmulo (Portto et al., 2006). Pesquisas já vêm sendo desenvolvidas com enfoque no uso de adsorventes naturais. Arruda (2003) compara a capacidade adsortiva de resíduos de maçã, casca de arroz e esponja natural. Já Reis et al. (2005) estuda o uso de casca de café, enquanto Silva et al. (2013) e Solto et al (2-13) avalia a utilização de fibra de coco verde, como adsorventes de metais pesados.

O café é o segundo produto de maior comercialização no mundo, e o Brasil, o seu maior produtor. A quantidade de resíduos gerados no beneficiamento do café ocorre na proporção de 1:1 em relação à produção, ou seja, para cada tonelada de café beneficiado, uma tonelada de resíduo é gerada. Esses resíduos vêm ganhando espaço cada vez maior porque além de representarem matéria-prima de baixo custo e abundante, também podem causar efeitos nocivos ao meio ambiente quando descartados de forma inadequada (Oliveira et al., 2012).

Usando planejamentos experimentais baseados em princípios estatísticos é possível determinar um máximo de informação útil, com o mínimo de esforços experimentais. Para isso existem técnicas eficazes disponíveis para melhorar ou otimizar sistemas, processos e produtos (Box et al., 1978). No planejamento fatorial $3^{\mathrm{k}}$ tem-se $\mathrm{k}$ fatores avaliados em três níveis denotados por baixo (-1), médio (0) e alto (+1). Ele é usado quando se está interessado em detectar curvatura na função de resposta, uma vez que o modelo de regressão é dado pela Equação:

$$
Y=\beta_{0}+\beta_{1} x_{1}+\beta_{2} x_{2}+\beta_{12} x_{1} x_{2}+\beta_{11} x_{1}^{2}+\beta_{22} x_{2}^{2}+\varepsilon
$$

O presente trabalho tem como objetivo utilizar o resíduo do beneficiamento do café como 
material adsorvente para o tratamento do efluente oleoso de uma oficina de mecânica pesada de uma indústria mineradora. O estudo será realizado utilizando-se a determinação do teor de óleos e graxas. Serão testadas a melhor condição de $\mathrm{pH}$, concentração de adsorvente e tempo de contato.

\section{MATERIAIS E MÉTODOS}

O preparo do material adsorvente se deu através da separação das impurezas seguida de lavegem em água corrente até o estado de não tingimento da água. Após, foram secas em estufa a $105^{\circ} \mathrm{C}$ por $24 \mathrm{~h}$ (Reis et al., 2005). As cascas de café foram utilizadas in natura, e para controle da granulometria de partículas, optou-se por utilizar a faixa granulométrica mais representativa da amostra disponível. Para tanto, as cascas foram peneiradas. A fração mássica que ficou retida na peneira de 9 mesh foi significativamente maior que as demais, sendo essa, portanto, a faixa utilizada.

Para a determinação de óleos e graxas da amostra foi utilizado o teste de Teor de Óleos e Graxas (TOG) (Clesceri, 1998). Uma alíquota de $30 \mathrm{~mL}$ foi retirada da amostra de água oleosa, e acidificada até pH 2 com solução aquosa de $\mathrm{H}_{2} \mathrm{SO}_{4} 0,1 \mathrm{M}$. A amostra foi então vertida em funil de separação e a extração foi realizada três vezes, utilizando $10 \mathrm{~mL}$ de n-hexano a cada extração. A fração de n-hexano foi levada para estufa a $100{ }^{\circ} \mathrm{C}$ para que o $\mathrm{n}$-hexano evapore. $\mathrm{O}$ Teor de Óleos e Graxas foi realizado em duplicata e determinado pela Equação:

$$
C=\left(m_{f}-m_{i}\right) \frac{1000}{0,03}
$$

Em que, $C$ é a concentração de óleos e graxas, em mg/L; $m_{f}$ e $m_{i}$ são as massas do béquer depois e antes do procedimento de TOG, em gramas.

$\mathrm{O} \mathrm{pH}$ das amostras de água oleosa foram ajustados com uso de $\mathrm{H}_{2} \mathrm{SO}_{4} 0,1 \mathrm{M}$ e $\mathrm{KOH} \mathrm{0,1} \mathrm{M}$ para 3, 7 e 11, sendo as leituras de $\mathrm{pH}$ executadas com o auxílio de medidor de pH mPA210 MSTECNOPON®. Os testes de adsorção foram realizados com concentração de adsorvente igual a $1 \mathrm{~g} / 100 \mathrm{~mL}$ de água oleosa por uma hora a $100 \mathrm{rpm}$, utilizando Jar Teste Microcontrolado SPLabor®. Após o período de adsorção, as amostras foram peneiradas para remoção da casca de café e uma alíquota de $30 \mathrm{~mL}$ foi tomada para realização do TOG.

Os testes de adsorção foram realizados no $\mathrm{pH}$ ótimo. Foram estudados o tempo de contato $(1,2$ e 3 h) e a concentração de casca de café $(0,5 ; 1$ e 2 g/100 mL de água oleosa) sob agitação à $100 \mathrm{rpm}$ com uso de jar teste. A Figura 1 expõe uma representação esquemática do procedimento realizado.

Para a realização desses experimentos utilizou-se planejamento estatístico fatorial do tipo $3^{2}$, totalizando 9 experimentos, tendo como níveis baixo, médio e alto, respectivamente, 1,2 e 3 horas e 0,$5 ; 1,0$ e $2,0 \mathrm{~g} / 100 \mathrm{~mL}$. O procedimento foi realizado em duplicata e a variável resposta foi a concentração, em mg/L, de óleos e graxas do efluente em estudo medido por meio do TOG. 


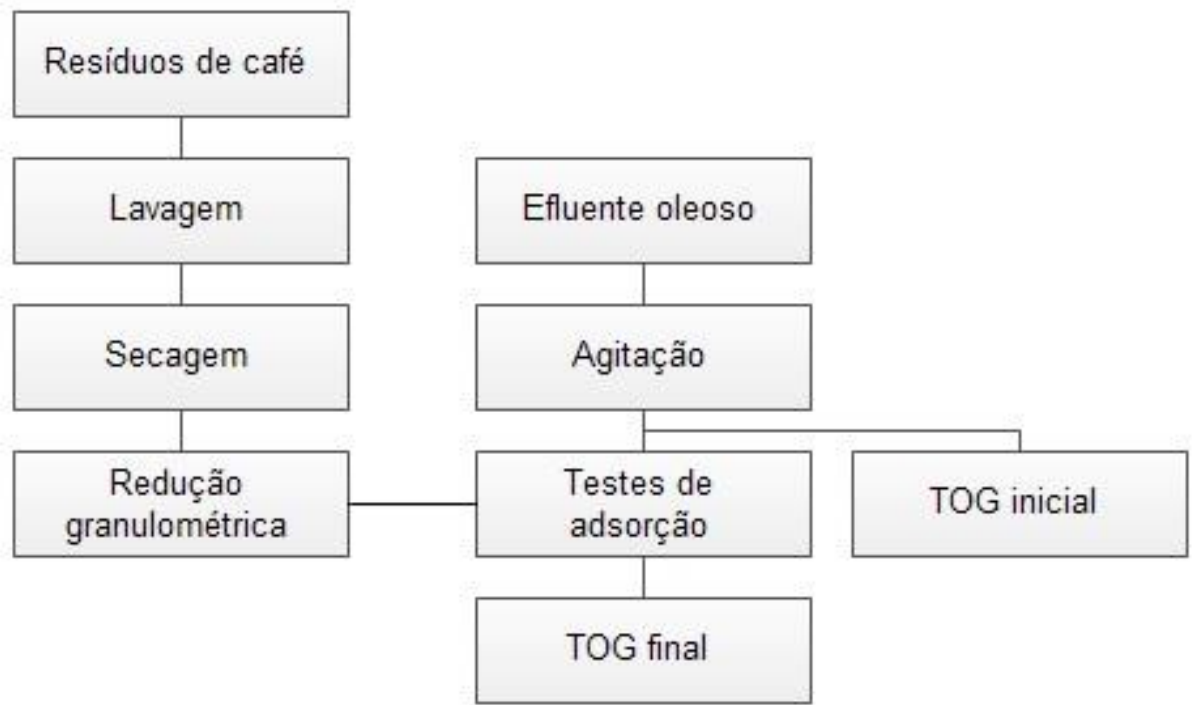

Figura 1 - Fluxograma do procedimento de adsorção.

\section{RESULTADOS E DISCUSSÃO}

\section{1. pH Ótimo de Adsorção}

Utilizando-se o método TOG apresentado na metodologia, caracterizou-se o efluente oleoso. A concentração de óleos e graxas obtida utilizando-se a Equação 2 foi de $140 \mathrm{mg} / \mathrm{L}$. Para o estudo do $\mathrm{pH}$ ótimo de adsorção, a concentração de adsorvente na solução e o tempo foram mantidos constantes. Os pHs das soluções foram ajustados para 3, 7 e 11. Os resultados obtidos encontram-se na Tabela 1.

Tabela 1 - Efeito do pH nos ensaios de adsorção

\begin{tabular}{ccc}
\hline $\mathbf{p H}$ & Concentração final (mg/L) & \% Remoção \\
\hline 3 & 70,00 & 50 \\
7 & 98,33 & 30 \\
11 & 73,33 & 48 \\
\hline
\end{tabular}

Pelos resultados obtidos foi possível determinar que a condição de $\mathrm{pH}$ ótimo para a adsorção de óleos e graxas do efluente oleoso utilizando cascas de café é o ácido, tendo em vista que a menor concentração de óleos e graxas foi observada neste $\mathrm{pH}$, indicando uma maior remoção, $50 \%$, em relação à concentração inicial. Este resultado era esperado visto que a quebra de emulsões ocorre mais facilmente em meio ácido.

\subsection{Testes de Adsorção}

A partir do resultado da etapa anterior, realizaram-se os testes de adsorção, conforme o 
planejamento experimental, com o pH fixo em 3. As condições estudadas foram concentração de adsorvente e tempo de contato. A Tabela 2 apresenta os resultados obtidos.

Tabela 2 - Concentrações e percentuais de remoção nos correspondentes tempos de contato e concentração de adsorvente

\begin{tabular}{cccc}
\hline $\begin{array}{c}\text { Tempo } \\
(\mathbf{m i n})\end{array}$ & $\begin{array}{c}\text { Concentração Adsorvente } \\
(\mathbf{g} / \mathbf{1 0 0} \mathbf{m L})\end{array}$ & Concentração $(\mathbf{m g} / \mathbf{L})$ & \% Remoção \\
\hline \multirow{3}{*}{60} & 0,5 & 28,33 & 80 \\
& 1,0 & 63,33 & 55 \\
& 2,0 & 68,33 & 51 \\
\cline { 2 - 4 } 120 & 0,5 & 35,00 & 75 \\
& 1,0 & 26,67 & 81 \\
& 2,0 & 15,00 & 85 \\
\hline \multirow{2}{*}{180} & 0,5 & 38,33 & 73 \\
& 1,0 & 61,67 & 56 \\
& 2,0 & 20,00 & 86 \\
\hline
\end{tabular}

Pelos resultados obtidos verifica-se que o percentual de remoção de óleos e graxas do efluente em análise foi superior a $50 \%$ em todos os ensaios. Entretanto, não é possível identificar uma tendência de relação entre a resposta e as variáveis estudadas.

Os dados de tempo e concentração de adsorvente foram tratados no software Statistica®. Foi atribuído que o nível de significância é de 95\%, portanto, a variável só exerce influência sobre a resposta quando o p-valor é menor do que 5\%, significando que a média de concentrações obtidas estará dentro desse intervalo (Calado e Montgomery, 2003). Os dados do efeito e do p-valor, extraídos da tabela de ANOVA gerada pelo software Statistica ${ }^{\circledR}$, estão na Tabela 3.

Tabela 3 - Estimativas de efeito

\begin{tabular}{cccc}
\hline Fator & Efeito & p-valor & Coeficiente \\
\hline Concentração (L) & 0,5556 & 0,9368 & 0,2778 \\
Concentração (Q) & 16,4815 & 0,0185 & 8,2407 \\
Tempo (L) & $-16,6667$ & 0,0330 & $-8,3333$ \\
Tempo (Q) & $-21,1111$ & 0,0040 & $-10,5556$ \\
Interaçãa (LxL) & $-30,0000$ & 0,0034 & $-15,0000$ \\
\hline
\end{tabular}

Pela análise da Tabela 3, os fatores Concentração (Q), Tempo (L), Tempo (Q) e Interação $(\mathrm{LxL})$ foram significativos, o que indica que esses parâmetros exercem influência no processo de adsorção de óleos e graxas pela casca de café.

O ajuste da concentração ao modelo foi satisfatório, já que, como mostra a Figura 2-a, os pares de pontos estão próximos à reta, caracterizando uma distribuição normal; e, o gráfico residual da variável concentração está perfeitamente aleatório, conforme a Figura 2-b. 


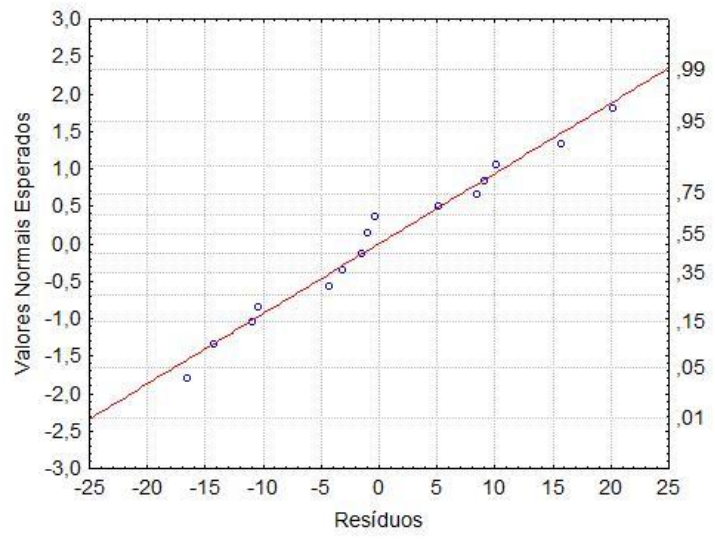

(a)

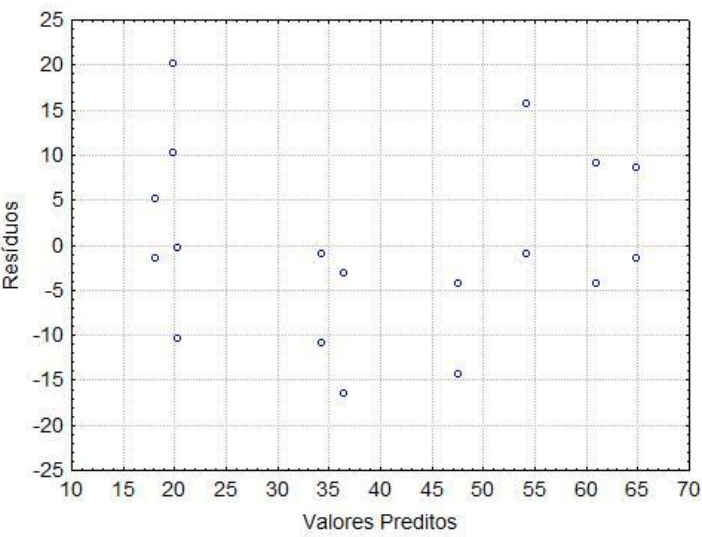

(b)

Figura 2 - (a) Normalidade dos ensaios; (b) Resíduos da variável concentração de óleos e graxas.

A sensibilidade dos parâmetros estudados sobre a resposta de interesse é examinada através do Diagrama de Pareto, Figura 3-a, que indica quais parâmetros e interações têm influências significativas sobre a variável resposta (Barbosa, 2009). Para identificar a resposta ótima, utilizam-se os gráficos de superfície, Figura 3-b.

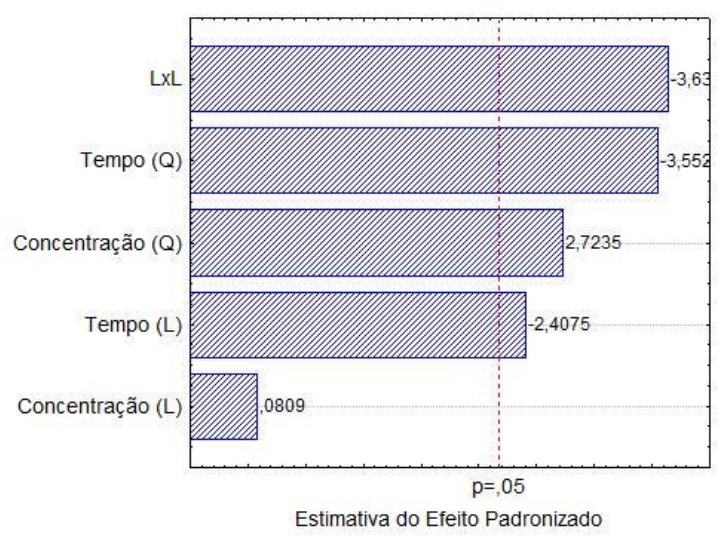

(a)

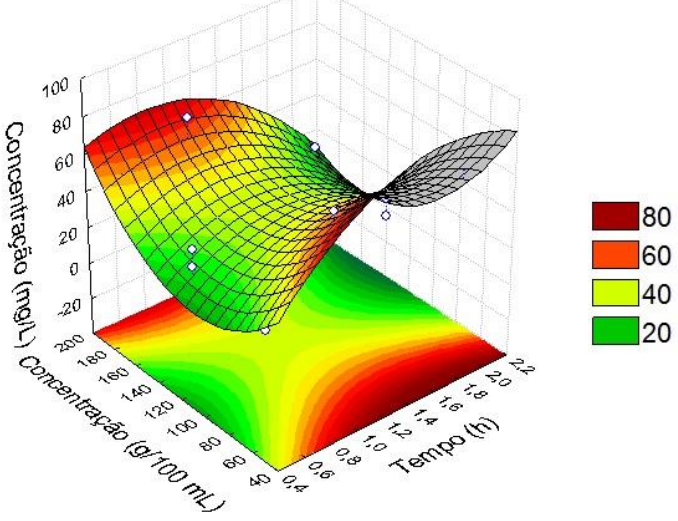

(b)

Figura 3 - (a) Diagrama de Pareto; (b) Gráfico de superfície para os ensaios de adsorção.

Pode-se identificar pela Figura 3-a que o efeito da Interação (LxL) e do Tempo (Q) são significativamente maiores do que os outros fatores analisados, e que o efeito da Concentração (L) pode ser negligenciado.

Deseja-se encontrar os níveis das variáveis independentes que maximizam a resposta estimada. Este ponto, se existir, pode ser de máximo, de mínimo ou de sela. Para o estudo em análise, a superfície obtida é um parabolóide hiperbólico (sela), Figura 3-b; neste caso, não é 
possível determinar um ponto ótimo para o fenômeno estudado, devido ao fato de que neste tipo de superfície não há somente um ponto máximo ou um ponto mínimo, isto é, um mesmo ponto é máximo relativo em uma direção e mínimo em outra.

Diversas pesquisas nas mais variadas áreas já encontraram pontos de sela como resultado. Gargantini et al. (2005), por exemplo, localizou um ponto de sela em seu estudo sobre o cultivo de capim Mombaça na região oeste do estado de São Paulo. Já na análise sobre a umidade do solo e doses de potássio na cultura de soja, Serafim et al. (2012) teve a interpretação do efeito da umidade comprometido também pela presença de um ponto de sela.

A presença de um ponto de sela para tempos superiores a $0,8 \mathrm{~h}$ e concentrações de adsorvente acima de $80 \mathrm{~g} / 100 \mathrm{~mL}$ comprometem a interpretação do efeito da concentração. $\mathrm{O}$ ponto de sela é indicativo de uma região estacionária onde a resposta concentração tem efeito desprezível em função do efeito das variáveis. A fim de se otimizar o processo, pesquisas adicionais devem ser realizadas utilizando uma faixa mais estreita dentro das regiões de máximo e mínimo do gráfico de superfície.

\section{CONCLUSÕES}

$\mathrm{O}$ pH ácido é o mais adequado para adsorção de óleos e graxas utilizando cascas de café. O ajuste da concentração ao modelo foi satisfatório e segue uma distribuição normal, tendo em vista a distribuição aleatória dos resíduos.

Concentração de adsorvente e tempo de contato são fatores que influenciam, tanto dependente quanto independentemente, no processo adsortivo estudado. Além disso, pode-se verificar que enquanto o efeito da Concentração (L) pode ser desprezado, o efeito da Interação (LxL) e do Tempo (Q) são substancialmente maiores do que os outros fatores analisados. Quanto à otimização do processo em estudo, nas condições em que os ensaios foram realizados, não é possível determinar uma combinação de fatores que apresente um ponto ótimo, confirmando falta de tendência de relação entre a resposta e as variáveis estudadas, indicando uma região ótima que de ser estudada.

Baseando-se nos testes e nas análises realizados, conclui-se que a casca de café é um potencial material adsortivo para óleos e graxas.

\section{REFERÊNCIAS}

ARRUDA, M. A. Z. Materiais naturais empregados como sorventes no tratamento de efluentes: perspectivas e aplicações. VIII Encontro Nacional sobre Métodos dos Laboratórios da Embrapa. Jaguariúna-SP, 2003.

BARBOSA, J. M. D. Influência da areia argilosa na recuperação de petróleo por injeção de vapor. Natal-RN, 2009.

BOX, G. E. P.; HUNTER, W. G.; HUNTER, J. S. Statistics for Experiments. J. Wiley \& Sons, 1978. 
CALADO, V.; MONTGOMERY, D. C. Planejamento de experimentos usando o Statistica. Rio de Janeiro: E-Papers, 2003.

CLESCERI, L. S.; GREENBERG, A. E.; EATON, A. D. Standard Methods for the examination of water and wastewater. 20. Ed. American Public Health Association, 1998.

FAGUNDES, A.; CUNHA, D.; CRAVEIRO, I.; PEREIRA, J.; GUIMARÃES, T.; SOUSA, V. Tratamento de efluentes da indústria têxtil por adsorção em materiais de baixo custo. Projeto FEUP. Porto, 2010.

GARGANTINI. P. E.; HERNANDEZ F. B. T.; VANZELA L. S.; LIMA R. C. Irrigação e adubação nitrogenada em capim mombaça na Região oeste do estado de São Paulo. XV Congresso Nacional de Irrigação e Drenagem. Teresina - PI, 2005.

OLIVEIRA, L. K.; CASTRO, S.F.; BERTECHINI, A. G.; LIMA, E. M. C.; ESPÓSITO, M.; BIANCHI, M. L. Desenvolvimento de materiais adsorventes de óleos a partir de resíduos do beneficiamento do café e sua aplicação na ração para aves. Rev. Bras. Saúde Prod. Anim. v. 13, n. 4, Salvador, 2012.

PERUZZO, L. C. Influência de agentes auxiliares na adsorção de corantes de efluentes da indústria têxtil em colunas de leito fixo. Dissertação de Mestrado. UFSC. Florianópolis-SC, 2003.

PORTTO, A.; ARCHER, L.B.; MACHADO, V. G.; MACHADO, C. Investigação da capacidade adsorvente de um resíduo agrícola (sabugo de milho) na remoção de cor. $29^{a}$ Reunião Anual da Sociedade Brasileira de Química. São Paulo, 2006.

REIS, M. O.; OLIVEIRA, L. S.; ROCHA, S. D. Adsorvente de resíduos do beneficiamento de café. VI Congresso Brasileiro de Engenharia Química em Iniciação Científica. Campinas, 2005.

SANTOS, E. G.; ALSINA, O. L. S.; SILVA, F. L. H. Desempenho de biomassas na adsorção de hidrocarbonetos leves em efluentes aquosos. Quím. Nova. v. 30, n. 2, 2007.

SERAFIM, M. E.; ONO, F. B.; ZEVIANI, W. M.; NOVELINO, J. O.; SILVA, J. V. Umidade do solo e doses de potássio na cultura da soja. Rev. Ciênc. Agron. v. 43, n. 2, p. 222-227, abr-jun, 2012.

SILVA, K. M. D.; REZENDE, L. C. S. H.; SILVA, C. A.; BERGAMASCO, R.; GONÇALVES, D. S. Caracterização físico-química da fibra de coco verde para a adsorção de metais pesados em efluente de indústria de tinta. ENGEVISTA. v. 15. n. 1. abr, 2013. 